\title{
Predictors of specific anti-Brucella antibodies among humans in agro-pastoral communities in Sengerema district, Mwanza, Tanzania: the need for public awareness
}

Elifuraha B. Mngumi ${ }^{1}$, Mariam M. Mirambo ${ }^{2 *}$, Sospeter Wilson ${ }^{2}$ and Stephen E. Mshana ${ }^{2}$

\begin{abstract}
Background: Human brucellosis remains to be a neglected zoonotic disease among agro-pastoral communities where livestock rearing is one of the main economic activities. This study was conducted in different agro-pastoral communities in Sengerema district, Mwanza, Tanzania, to determine seroprevalence and predictors of anti-Brucella antibodies, information that may influence public awareness on the risk factors and strategies to improve the diagnosis of brucellosis in developing countries.

Methods: A cross-sectional community-based study was conducted between July and September 2008 in ten villages of Sengerema district. Sociodemographic and other related information were collected using a standardized data collection tool. Detection of Brucella abortus and Brucella melitensis antibodies were done using rapid Brucella serum agglutination test. Data were analysed by using STATA version 11.0. Adjusted odds ratios (AOR) were calculated using multivariate logistic regression analysis.

Results: A total of 382 adults were enrolled with the median age of 30 (interquartile range 15-40) years. Males formed the majority of the participants 234 (61.5\%). Overall, seroprevalence of anti-Brucella antibodies was found to be $14.1 \%(54 / 382$, $95 \%$ Cl 10.6-17.5). Seroprevalence of B. melitensis was $11 \%(42 / 382)$ while that of B. abortus was found to be $7 \%(26 / 282), P=0.0267$. Co-infection of B. melitensis and B. abortus was observed in $3.6 \%(14 / 382$, $95 \% \mathrm{Cl} 1.7-5.4$ ) of participants. On a multivariate logistic regression analysis, male sex (AOR 3.2, $95 \% \mathrm{Cl} 1.3-7.5$, $P=0.007$ ), touching goat placenta (AOR $2.54,95 \% \mathrm{Cl} 1.05-6.14, P=0.012$ ) and agro-pastoralist occupation (AOR 2. $07,95 \% \mathrm{Cl} 1.01-4.24, P=0.04$ ) were found to predict B. melitensis infection. Males (AOR 3.07, $95 \% \mathrm{Cl} 1.45-6.51$, $P=0.003$ ) and agro-pastoralists (AOR $2.98,95 \% \mathrm{Cl} 1.38-6.43, P=0.005)$ were found to be predictors for specific anti-Brucella antibodies.

Conclusions: A significant proportion of the agro-pastoralist male population in agro-pastoral communities in Sengerema district is positive for anti-Brucella antibodies. With the decrease incidence of malaria fever, other causes of fever such as Brucella spp. should be considered of public health concern in Tanzania especially in agro-pastoral communities.
\end{abstract}

Keywords: B. abortus, B. melitensis, Brucellosis, Anti-Brucella antibodies, Sengerema

\footnotetext{
* Correspondence: mmmirambo@gmail.com

${ }^{2}$ Department of Microbiology and Immunology, Weill Bugando School of Medicine, Catholic University of Health and Allied Sciences, P.O. Box 1464, Mwanza, Tanzania

Full list of author information is available at the end of the article
} International License (http://creativecommons.org/licenses/by/4.0/), which permits unrestricted use, distribution, and reproduction in any medium, provided you give appropriate credit to the original author(s) and the source, provide a link to the Creative Commons license, and indicate if changes were made. The Creative Commons Public Domain Dedication waiver (http://creativecommons.org/publicdomain/zero/1.0/) applies to the data made available in this article, unless otherwise stated. 


\section{Background}

Human brucellosis is a global public health concern due to its potential in causing morbidity among human population as well as livestock leading to economic loses. Worldwide, over 500,000 human cases of brucellosis are reported annually [1]. Seroprevalence has been found to vary in different countries across Sub-Saharan Africa [1, 2]. In the tropical countries like Tanzania, Brucella infection is endemic especially in agro-pastoral communities [2]. Brucellosis is an occupational disease to slaughterhouse workers, agro-pastoralists, laboratory personnel and veterinarians [3]. Humans can get infection through direct contact with infected farm animals or ingestion of contaminated animal products [4, 5].

Brucella infection is characterized by non-specific symptoms including general body malaise, anorexia, fever, back pain, headache, lethargy and many other clinical presentations that often mimic other diseases causing pyrexia such as malaria and typhoid fever [2, 6-8]. Its ability to survive and multiply within immune cells such as macrophages results into chronic debilitating disease with poor prognosis in most of the cases [9]. In addition, the treatment requires multiple antibiotics for prolonged duration. Despite being important, zoonotic disease data regarding the epidemiology of Brucella infection among high-risk groups are scarce in developing countries including Tanzania.

Tanzania is a Third World country which has about 51 million people. About $68 \%$ of the Tanzania population is below the poverty line of $\$ 1.25$ per day [10] and is involved in small-scale agricultural activities. Sengerema district has a total population of 663,034 with the majority of them engaged in agro-pastoralist activities. The poverty and agro-pastoralist activities are risk factors for neglected diseases include brucellosis [11].

This study was conducted to determine seroprevalence and predictors of Brucella infection among agro-pastoral communities in Sengerema district. This information may be useful in influencing public awareness on the possible risk factors for infection as well as considering it in diagnosis of febrile illnesses especially in these communities.

\section{Methods}

\section{Data collection and laboratory procedures}

A cross-sectional community-based study was carried out between July and September 2008 in ten agro-pastoral villages in Sengerema district namely Kasungamile, Kabusuli, Lubungo, Magutu, Mami, Ngoma A, Ngoma B, Nyalwambu, Sota and Sota Kaningu. Sociodemographic data and other information related to brucellosis (age, sex, keeping cattle, contact with blood, touching animal placenta, consuming raw milk etc.) were collected using a standardized data collection tool. After obtaining written informed consent, about $4 \mathrm{ml}$ of blood samples were collected using plain Vacutainer tubes (Becton, Dickinson and Company, Nairobi, Kenya) and transported to the Bugando multipurpose laboratory whereby sera were separated and stored in cryovials at $-80{ }^{\circ} \mathrm{C}$ until processing. Sera were tested for the presence of specific Brucella melitensis and Brucella abortus antibodies using commercial rapid agglutination test according to the manufacturer's instructions (Eurocell A/ $\mathrm{M}^{\circ}$ Euromedi equip LTD.UK). The Eurocell $\mathrm{A}^{\star}$ is specific for B. abortus and Eurocell $\mathrm{M}^{\ominus}$ for $B$. melitensis. The agglutination test has been found to have $95 \%$ sensitivity with specificity of $100 \%$ [12].

\section{Data management and analysis}

Data were entered into a computer using Microsoft Office Excel 2007 and analysed using the STATA version 11 (College Station, Texas, USA). Categorical variables were presented as proportions while continuous variables (age) were summarized as median with interquartile ranges. Stepwise regression model was used to determine factors associated with anti-Brucella antibodies. Univariate analysis was done, and factors with $P$ value $<0.2$ were fitted on multivariate logistic regression analysis. Unadjusted odds ratio (UAOR), adjusted odds ratio (AOR) and $95 \%$ confidence interval (CI) were noted. $P$ value of $<0.05$ was considered statistically significant.

\section{Results}

\section{Baseline characteristics}

A total of 382 participants from agro-pastoral communities in different villages of Sengerema district were recruited with the median age of 30 (interquartile range (IQR) 15-40) years. Males 234 (61.5\%) formed the majority of the study population. Out of 382 participants, $117(30.6 \%)$ and 245 (64.1\%) were students and agropastoralists, respectively. A total of 294 (77 \%) participants were found to keep cattle (Table 1).

\section{Prevalence of specific anti-Brucella antibodies}

Overall, seroprevalence of brucellosis was found to be $14.1 \%$ (54/382, 95 \% CI 10.6-17.5). Seroprevalence of B. melitensis antibodies was found to be $11 \%(42 /$ 382, $95 \%$ CI 7.8-14.1) while for B. abortus was $7 \%$ (26/282, 95 \% CI 4.4-9.5), $P=0.026$. Seroprevalence of anti-Brucella antibodies indicative of co-infection with both $B$. melitensis and B. abortus was found to be $3.6 \%$ (14/382, $95 \%$ CI 1.7-5.4).

Factors associated with the presence of specific anti-Brucella antibodies

The median age of participants who tested positive for B. melitensis antibodies was 30 (IQR 19-40) years 
Table 1 Baseline characteristics of 382 adult participants from Sengerema district

\begin{tabular}{lll}
\hline Characteristics & Frequency/median & Percent \\
\hline Age & 30 (IQR 15-40) & \\
Sex & 148 & 38.5 \\
$\quad$ Female & 234 & 61.5 \\
$\quad$ Male & & \\
Occupation & 117 & 30.6 \\
$\quad$ Students & 245 & 64.1 \\
Agro-pastoralists & 20 & 5.2 \\
$\quad$ Others & \\
Keep cattle & & \\
No & 88 & 23.0 \\
Yes & 294 & 77.0 \\
\hline Businessmen, teachers and fishermen
\end{tabular}

${ }^{\mathrm{a} B u s i n e s s m e n, ~ t e a c h e r s ~ a n d ~ f i s h e r m e n ~}$

compared to 30 (IQR 15-40) years for those tested negative $(P=0.489)$. Males had significantly higher $B$. melitensis antibodies than females (14.5 vs. $5.4 \%, P=$ 0.008). On multivariate logistic regression analysis, male sex (AOR 3.2, $95 \% \mathrm{CI} 1.3-7.5, P=0.007$ ), touching goat placenta (AOR 2.54, $95 \%$ CI 1.05-6.14, $P=0.012$ ) and agro-pastoralist occupation (AOR 2.07, 95 \% CI 1.01-4.24, $P=0.04)$ were found to predict $B$. melitensis infection (Table 1).
Regarding B. abortus, there was no significant difference between male and female sex $(8.5$ vs. $4.1 \%, P=0.097)$. On univariate logistic regression analysis, agro-pastoralists were more likely to contract B. abortus infection than students (OR 7.3, 95 \% CI $1.71-31.51, P=0.007$ ). Only occupation (OR 7.44, $95 \%$ CI 1.42-38.9, $P=0.02$ ) remained significant predicting $B$. abortus infection when adjusted for age, touching placenta, touching goat placenta and blood splash (Table 2).

Overall, males (18.4 vs. $7.4 \%, P=0.004)$ and agropastoralists (18.0 vs. $8.5 \%, P=0.005)$ had significantly higher rates of Brucella-specific antibodies than females and students, respectively (Table 3 ). These factors were independently found to be associated with Brucella infection with either of the two species (Table 4). On multivariate logistic regression analysis, male sex (OR $3.07,95 \% \mathrm{CI} 1.45-6.51, P=0.003)$ and being agropastoralist (OR 2.98, $95 \%$ CI 1.38-6.43, $P=0.005$ ) were found to predict the presence of Brucella-specific antibodies when adjusted to touching placenta and touching goat placenta.

\section{Discussion}

Brucellosis is one of the public health concerns due its potential in causing human infection and economic loses among agro-pastoralists [13]. Despite having impact on livelihoods, it is one of the neglected tropical diseases in

Table 2 Factors associated with B. melitensis seropositivity among 382 adults from agro-pastoral communities in Sengerema district

\begin{tabular}{|c|c|c|c|c|c|}
\hline Characteristics & B. melitensis seropositivity & Unadjusted OR (95\% Cl) & $P$ value & Adjusted OR (95\% Cl) & $P$ value \\
\hline Age (years)* & 42 (IQR 19-40) & $1.0(0.98-1.02)$ & 0.628 & & \\
\hline \multicolumn{6}{|l|}{ Sex } \\
\hline Female (148) & $8(5.4 \%)$ & 1 & & & \\
\hline Male (234) & 34 (14.5\%) & $2.9(1.33-6.62)$ & 0.008 & $3.2(1.3-7.5)$ & 0.007 \\
\hline \multicolumn{6}{|l|}{ Occupation } \\
\hline Students (117) & $10(8.5 \%)$ & 1 & & & \\
\hline Agro-pastoralists (245) & $32(13.1 \%)$ & $1.9(0.90-4.01)$ & 0.088 & $2.07(1.01-4.24)$ & 0.04 \\
\hline \multicolumn{6}{|l|}{ Keep cattle } \\
\hline No (88) & 9 (10.2\%) & 1 & & & \\
\hline Yes (294) & $33(11.2 \%)$ & $1.1(0.5-2.41)$ & 0.793 & & \\
\hline \multicolumn{6}{|l|}{ Touch placenta } \\
\hline No (289) & $28(9.7 \%)$ & 1 & & & \\
\hline Yes (93) & $14(15.1 \%)$ & $1.65(0.82-3.29)$ & 0.153 & $0.75(0.34-1.67)$ & 0.493 \\
\hline \multicolumn{6}{|l|}{ Touch goat placenta } \\
\hline No (341) & $32(9.4 \%)$ & 1 & & & \\
\hline Yes (41) & $10(24.4 \%)$ & $3.11(1.4-6.9)$ & 0.005 & $2.59(1.25-6.38)$ & 0.012 \\
\hline \multicolumn{6}{|l|}{ Blood splash } \\
\hline No (360) & 37 (10.3\%) & 1 & & & \\
\hline Yes (22) & $5(22.7 \%)$ & $2.5(0.89-7.4)$ & 0.079 & $1.5(0.47-4.98)$ & 0.47 \\
\hline
\end{tabular}


Table 3 Factors associated with B. abortus seropositivity among 382 adults from agro-pastoral communities in Sengerema district

\begin{tabular}{|c|c|c|c|c|c|}
\hline Characteristics & B. abortus seropositivity & Unadjusted OR (95% Cl) & $P$ value & Adjusted OR (95\% Cl) & $P$ value \\
\hline Age (years)* & 30 (IQR 23-47) & $1.02(0.99-1.04)$ & 0.069 & $0.98(0.96-1.01)$ & 0.489 \\
\hline \multicolumn{6}{|l|}{ Sex } \\
\hline Female (148) & $6(4.05 \%)$ & 1 & & & \\
\hline Male (234) & $20(8.5 \%)$ & $2.2(0.87-5.64)$ & 0.097 & $2.1(0.753-6.14)$ & 0.152 \\
\hline \multicolumn{6}{|l|}{ Occupation } \\
\hline Students (117) & $2(1.7 \%)$ & 1 & & & \\
\hline Agro-pastoralists (245) & $24(9.8 \%)$ & $7.3(1.71-31.51)$ & 0.007 & $7.44(1.42-38.9)$ & 0.017 \\
\hline \multicolumn{6}{|l|}{ Keep cattle } \\
\hline No (88) & $4(4.55 \%)$ & 1 & & & \\
\hline Yes (294) & $22(7.5 \%)$ & $1.69(0.57-5.07)$ & 0.342 & & \\
\hline \multicolumn{6}{|l|}{ Touch placenta } \\
\hline No (289) & $14(4.84 \%)$ & 1 & & & \\
\hline Yes (93) & $12(12.9 \%)$ & $2.9(1.29-6.5)$ & 0.010 & $1.35(0.52-3.4)$ & 0.529 \\
\hline \multicolumn{6}{|l|}{ Touch goat placenta } \\
\hline No (341) & $20(5.87 \%)$ & 1 & & & \\
\hline Yes (41) & $6(14.63 \%)$ & $2.7(1.04-7.3)$ & 0.042 & $1.76(0.59-5.27)$ & 0.307 \\
\hline \multicolumn{6}{|l|}{ Blood splash } \\
\hline No (360) & $22(6.11 \%)$ & 1 & & & \\
\hline Yes (22) & 4 (18.2 \%) & $3.4(1.06-10.9)$ & 0.034 & $1.89(0.52-6.88)$ & 0.329 \\
\hline
\end{tabular}

*Median

Table 4 Factors associated with Brucellosis among 382 adults from agro-pastoral communities in Sengerema district

\begin{tabular}{|c|c|c|c|c|c|}
\hline Characteristics & Brucellosis & Unadjusted OR (95% Cl) & $P$ value & Adjusted OR (95 \% Cl) & $P$ value \\
\hline Age (years)* & 30 (IQR 20-44) & $1.01(0.99-1.02)$ & 0.227 & & \\
\hline \multicolumn{6}{|l|}{ Sex } \\
\hline Female (148) & $11(7.43 \%)$ & & & & \\
\hline Male (234) & $43(18.38 \%)$ & $2.80(1.39-5.63)$ & 0.004 & $3.07(1.45-6.51)$ & 0.003 \\
\hline \multicolumn{6}{|l|}{ Occupation } \\
\hline Students (117) & $10(8.5 \%)$ & 1 & & & \\
\hline Agro-pastoralists (245) & $44(18.0 \%)$ & $2.7(1.35-5.72)$ & 0.005 & $2.98(1.38-6.43)$ & 0.005 \\
\hline \multicolumn{6}{|l|}{ Keep cattle } \\
\hline No (88) & $11(12.5 \%)$ & & & & \\
\hline Yes (294) & $43(14.6 \%)$ & $1.20(0.59-2.43)$ & 0.616 & & \\
\hline \multicolumn{6}{|l|}{ Touch placenta } \\
\hline No (289) & 35 (12.1\%) & & & & \\
\hline Yes (93) & $19(20.4 \%)$ & $1.86(1.01-3.45)$ & 0.048 & $0.86(0.42-1.75)$ & 0.687 \\
\hline \multicolumn{6}{|l|}{ Touch goat placenta } \\
\hline No (341) & $43(12.6 \%)$ & & & & \\
\hline Yes (41) & $11(26.8 \%)$ & $2.5(1.18-5.44)$ & 0.016 & $2.10(0.94-4.71)$ & 0.069 \\
\hline \multicolumn{6}{|l|}{ Blood splash } \\
\hline No (360) & 49 (13.6\%) & & & & \\
\hline Yes (22) & $5(22.7 \%)$ & $1.87(0.65-5.30)$ & 0.240 & & \\
\hline
\end{tabular}


most of the developing countries. Despite this study being conducted 8 years ago, the situation now is comparable to the time the study was conducted. In the present study, a significant proportion of agro-pastoralists was infected with $B$. melitensis which is comparable to previous studies [14-19]. On the contrary, the prevalence observed in this study is lower as compared to what has been reported earlier in Nigeria, Libya and Kenya [13, 20, 21]. The difference could be attributed by the fact that these previous studies were done among febrile patients and butcher workers which are among high-risk groups for brucellosis. In addition, the seroprevalence of $B$. abortus in this study was found to be significantly lower than that of $B$. melitensis which is in agreement with previous study [22].

Among the risk factors assessed, male sex, agropastoral occupation and touching goat placenta were found to be associated with $B$. melitensis infection among agro-pastoral communities which is consistent to previous reports $[14,20,23-27]$. Meanwhile, agropastoralism was the only factor found to predict $B$. abortus infection while male sex and agro-pastoralism were found to predict the presence of Brucella antibodies. The finding of touching goat placenta predicting $B$. melitensis infection confirms its presence in goat and sheep as the main host [28]. On the other side, male sex and agro-pastoralism were found to predict brucellosis as previously observed [29, 30]. Predominance of male sex and agro-pastoralism could be explained by the traditional roles of males in these communities whereby they are much more involved in livestock care as compared to female counterparts. Other studies have documented female sex to be risk factors for brucellosis, and this could be explained by female involvement in agro-pastoral activities, signifying the importance of occupation as the major risk factor for contracting Brucella infection [31].

One of the major limitations of the study is the recall bias; majority of the study participants might have forgotten the previous risk behaviour regarding brucellosis. The other limitation is inability to distinguish past and present infections. Despite these limitations, the information the data obtained will help in improving the diagnosis of other causes of fever in developing countries.

\section{Conclusions}

There is high seroprevalence of anti-Brucella antibodies among agro-pastoralists in Tanzania. With a decreased trend in malaria infections, diagnosis of other causes of febrile illnesses should be considered in these agropastoral communities.

\section{Abbreviations}

AOR: Adjusted odds ratio; BMC: Bugando Medical Centre; Cl: Confidence interval; CUHAS: Catholic University of Health and Allied Sciences;
IQR: Interquartile range; UAOR: Unadjusted odds ratio; VIC: Veterinary Investigation Centre

\section{Acknowledgements \\ The authors would like to acknowledge the technical support provided by \\ Mr. Vitus Silago and all the staff at Veterinary Investigation Centre (VIC) \\ Mwanza, Sengerema district council and Microbiology/Immunology \\ department-CUHAS-Bugando. This study was supported by a research grant from Touch Foundation to EBM.}

\section{Funding}

This study was supported by a research grant from CUHAS/Bugando to EBM.

Funders had no role in this study.

Availability of data and materials

All data have been included in the manuscript.

\section{Authors' contributions}

MMM, EBM and SEM participated in the design of the study. MMM and EBM did the data collection. SW performed the tests. MMM and SEM analysed and interpreted the data. MMM wrote the first draft of the manuscript. SEM and EBM did the critical review of the manuscript. All authors read and approved the final version of the manuscript.

Competing interests

The authors declare that they have no competing interests.

Consent for publication

Not applicable.

\section{Ethics approval and consent to participate}

The protocol for conducting the study was approved by the Joint Catholic University of Health and Allied Sciences/Bugando Medical Centre (CUHAS/BMC) research ethics and review committee (CREC) with ethical clearance number CREC/001/07/2007. Written informed consent was obtained from each participant prior recruitment to the study.

\section{Author details}

${ }^{1}$ Department of Veterinary Pathology, Sokoine University of Agriculture, P.O. Box 3018, Morogoro, Tanzania. ${ }^{2}$ Department of Microbiology and Immunology, Weill Bugando School of Medicine, Catholic University of Health and Allied Sciences, P.O. Box 1464, Mwanza, Tanzania.

Received: 8 July 2016 Accepted: 14 September 2016

Published online: 18 October 2016

References

1. Pappas G, Papadimitriou P, Akritidis N, Christou L, Tsianos EV. The new global map of human brucellosis. Lancet Infect Dis. 2006;6(2):91-9.

2. McDermott JJ, Arimi S. Brucellosis in Sub-Saharan Africa: epidemiology, control and impact. Vet Microbiol. 2002;90(1):111-34.

3. Pappas $G$, Akritidis N, Tsianos E. Effective treatments in the management of brucellosis. Expert Opin Pharmacother. 2005:6(2):201-9.

4. Makita K, Fèvre EM, Waiswa C, Kaboyo W, De Clare Bronsvoort BM, Eisler MC, Welburn SC. Human brucellosis in urban and peri-urban areas of Kampala, Uganda. Ann N Y Acad Sci. 2008;1149(1):309-11.

5. Corbel MJ. Brucellosis in humans and animals. Geneva: World Health Organization; 2006.

6. Kunda J, Fitzpatrick J, Kazwala R, French NP, Shirima G, MacMillan A, Kambarage D, Bronsvoort M, Cleaveland S. Health-seeking behaviour of human brucellosis cases in rural Tanzania. BMC Public Health. 2007:7(1):1.

7. Mutanda L. Selected laboratory tests in febrile patients in Kampala, Uganda. East Afr Med J. 1998;75(2):68-72.

8. Andriopoulos P, Tsironi M, Deftereos S, Aessopos A, Assimakopoulos G. Acute brucellosis: presentation, diagnosis, and treatment of 144 cases. Int J Infect Dis. 2007;11(1):52-7.

9. Roop II RM, Gaines JM, Anderson ES, Caswell CC, Martin DW. Survival of the fittest: how Brucella strains adapt to their intracellular niche in the host. Med Microbiol Immunol. 2009;198(4):221-38. 
10. Kazungu KG, Cheyo MB. Government expenditure on growth strategies and poverty reduction in Tanzania. What have we learned? Afr J Econ Rev. 2014; 2(1):38-47.

11. National Bureau of Statistics IM. Tanzania demographic and health survey 2010. 2011.

12. Memish Z, Almuneef M, Mah M, Qassem L, Osoba A. Comparison of the Brucella Standard Agglutination Test with the ELISA IgG and IgM in patients with Brucella bacteremia. Diagn Microbiol Infect Dis. 2002;44(2):129-32.

13. Ducrotoy MJ, Bertu WJ, Ocholi RA, Gusi AM, Bryssinckx W, Welburn S, Moriyon I. Brucellosis as an emerging threat in developing economies: lessons from Nigeria. PLoS Negl Trop Dis. 2014;8(7):e3008.

14. Tumwine G, Matovu E, Kabasa JD, Owiny DO, Majalija S. Human brucellosis: seroprevalence and associated risk factors in agro-pastoral communities of Kiboga District, Central Uganda. BMC Public Health. 2015;15(1):1.

15. Ogola E, Thumbi S, Osoro E, Munyua P, Omulo S, Mbatha P, Ochieng L, Marwanga D, Njeru I, Mbaabu M. Seroprevalence of brucellosis in humans and their animals: a linked cross-sectional study in two selected counties in Kenya. Online J Public Health Inform. 2014;6:1.

16. Sofian M, Aghakhani A, Velayati AA, Banifazl M, Eslamifar A, Ramezani A. Risk factors for human brucellosis in Iran: a case-control study. Int J Infect Dis. 2008;12(2):157-61.

17. Husseini AS, Ramlawi AM. Brucellosis in the West Bank, Palestine. Saudi Med J. 2004;25(11):1640-3

18. Kalaajieh W. Epidemiology of human brucellosis in Lebanon in 1997. Med Mal Infect. 2000;30(1):43-6.

19. Elbeltagy K. An epidemiological profile of brucellosis in Tabuk Province, Saudi Arabia. 2001

20. Ahmed M, Elmeshri S, Abuzweda A, Blauo M, Abouzeed Y, Ibrahim A, Salem $H$, Alzwam F, Abid S, Elfahem A. Seroprevalence of brucellosis in animals and human populations in the western mountains region in Libya, December 2006-January 2008. Euro Surveill. 2010;15(30):19625-8.

21. Muriuki S, McDermott J, Arimi S, Mugambi J, Wamola I. Criteria for better detection of brucellosis in the Narok District of Kenya. East Afr Med J. 1997; 74(5):317-20.

22. Swai ES, Schoonman L. Human brucellosis: seroprevalence and risk factors related to high risk occupational groups in Tanga Municipality, Tanzania. Zoonoses Public Health. 2009;56(4):183-7.

23. Wu G, Yang C. Prevalence study of brucellosis among high-risk people in Xinjiang region, China. Microbiol Discov. 2013;1(1):2.

24. Aworh MK, Okolocha E, Kwaga J, Fasina F, Lazarus D, Suleman I, Poggensee G, Nguku P, Nsubuga P. Human brucellosis: seroprevalence and associated exposure factors among abattoir workers in Abuja, Nigeria-2011. Pan Afr Med J. 2013;16:103.

25. Abdollahi A, Morteza A, Khalilzadeh O, Rasoulinejad M. Brucellosis serology in HIV-infected patients. Int J Infect Dis. 2010;14(10):e904-6.

26. Rahman AA, Dirk B, Fretin D, Saegerman C, Ahmed MU, Muhammad N, Hossain A, Abatih E. Seroprevalence and risk factors for brucellosis in a high-risk group of individuals in Bangladesh. Foodborne Pathog Dis. 2012;9(3):190-7.

27. Tsend S, Baljinnyam Z, Suuri B, Dashbal E, Oidov B, Roth F, Zinstag J, Schelling E, Dambadarjaa D. Seroprevalence survey of brucellosis among rural people in Mongolia. Western Pacific Surveill Res J. 2014;5(4):13.

28. Young EJ. Brucella spp. In: Principles and practice of clinical bacteriology 2nd ed. West Sussex, England: John Wiley \& Sons Ltd; 2006. p. 265-72.

29. Shirima G, Fitzpatrick J, Kunda J, Mfinanga G, Kazwala R, Kambarage D, Cleaveland S. The role of livestock keeping in human brucellosis trends in livestock keeping communities in Tanzania. Tanzan J Health Res. 2010; 12(3):203-7.

30. Assenga JA, Matemba LE, Malakalinga JJ, Muller SK, Kazwala RR. Quantitative analysis of risk factors associated with brucellosis in livestock in the KataviRukwa ecosystem, Tanzania. Trop Anim Health Prod. 2016:48(2):303-9.

31. Kansiime C, Rutebemberwa E, Asiimwe BB, Makumbi F, Bazira J, Mugisha A. Annual trends of human brucellosis in pastoralist communities of southwestern Uganda: a retrospective ten-year study. Infect Dis Poverty. 2015;4(1):1.

\section{Submit your next manuscript to BioMed Central and we will help you at every step:}

- We accept pre-submission inquiries

- Our selector tool helps you to find the most relevant journal

- We provide round the clock customer support

- Convenient online submission

- Thorough peer review

- Inclusion in PubMed and all major indexing services

- Maximum visibility for your research

Submit your manuscript at www.biomedcentral.com/submit
) Biomed Central 